\title{
Empirical Research on Cooperative Innovation Performance of Agricultural Scientific Research Team and Effect Factors $^{1}$
}

\author{
Li Peng ${ }^{1,2}$ \\ ${ }^{1}$ International Business School of Shaanxi Normal University, Xi'an, China \\ ${ }^{2}$ School of Economics and Management, Northwest A \& F University, Yangling, China
}

\begin{abstract}
:
With the expansion of agricultural scientific research activity areas, agricultural scientific research team or organization gradually developed into the basic unit of agricultural scientific research activity.Through the visit, discussion and small meeting communication or carry out questionnaire investigation, etc, investigated the situation of national agricultural scientific research innovation team, using DEA-Tobit model, measure the cooperative innovation performance of agricultural scientific research team, and analysied the direction and degree which environmental factors on agricultural scientific research team cooperative innovation

\footnotetext{
1 National Natural Science Foundation of China, Research on Non-market Value Assessment and Ecological Subsidy Mechanism of Diversified Straw Utilization Based on Choice Experiment Method (71703082); Postdoctoral Fund, Ecological Industry Chain, Heterogeneity of Beneficial Subjects and Straw Resourcefulness: Mechanism and Mechanism Design (2017M613233); Shaanxi Normal University Central University Basic Scientific Research Business Expenses Special Fund Project: Exploration of Science and Technology Precise Poverty Alleviation Model in Poverty-stricken Areas of Shaanxi from the Perspective of Social Embedding and Research on Enhancement Strategies(20200347).
} 
performance. The empirical results show that the mean of comprehensive efficiency was 0.4516, and with large room for improvement, the mean of pure technical efficiency was 0.6472, scale efficiency average was 0.6978 ; To improve the cognitive level of team goal can obviouslly improve the cooperative innovation performance, but title structure, familiar degree of Internal members, the rationality of expenditure is also decision elements of cooperative innovation performance. In addition, cross-team communication, local government support and relying on the unit properties to the innovation performance effects not get powerful data support, it is not obvious. According to the above, put forward the countermeasures and Suggestions of proposing stable investment mechanism, optimizing the internal structure, strengthening the cooperative innovation and so on.

Keywords : agricultural scientific research team;cooperative innovation performance; effect Factors; DEA - Tobit model

\section{Introduction}

Teamwork and collaboration have become important practices and tools in agricultural research activities. With the increasingly prominent role of agricultural research teams, scholars at home and abroad have conducted a lot of studies and researches on the management and innovation of science and technology teams, with different perspectives and approaches.

Regarding the definition of scientific research team, domestic and foreign scholars have achieved a relatively consistent view, that is, "a scientific research team has the general characteristics of a team, but also has its own uniqueness, and a scientific research team is a scientific research group with a stable organization (more than two people) that can cooperate with each other for the common purpose of scientific and technological exploration", and this concept is defined by the majority of scholars. This concept has received a lot of attention from scholars. With the increasing development of scientific research activities carried out by 
scientific research teams, collaborative research among scientific research teams can effectively integrate resources and promote scientific innovation, and scientific research teams are an effective way to transcend the traditional group concept, focus on collective performance and complementary capabilities of members, and achieve effective management of team members and organizational goals (Guoxian Bao 2010), which is verified by the application model of collaborative mechanism (Yang Wu 2012). The evaluation of scientific research team performance is also an important aspect studied and discussed by scholars at home and abroad, but the current evaluation of scientific research team performance stands more at the national or regional level, industry level or enterprise level (Eva Kirner 2009), mainly including R\&D teams of high-tech enterprises and scientific research teams of university disciplines, etc. The evaluation methods mainly include AHP fuzzy evaluation, scale analysis (Shang Runzhi 2010; Linlin Jin 2010), DEA (Ute R. Hülsheger et al. 2009), and constructing a quantitative index system (Xueguang Chen 2010). In the discussion of the factors influencing the innovation performance of research teams, the academic community has achieved a lot of results, and the views of scholars at home and abroad are basically consistent, considering that the size of the research team (James D. Adams 2005), the type of research tasks, the organizational team and the team leader (Hans J. Thamhain 2003; Huiqin Liu 2007), the social support received by the team support, internal equity and gender structure, team communication management (Yuwen Liu etal. 2011; Zhihong Li 2010; Bin Zhou 2012)), disciplinary background characteristics (Linlin Jin 2012), and collaborative goals (Zizhen Geng 2012) are factors that affect the operational performance of research teams. In addition, domestic scholars have also explored the influence of collaboration network characteristics on the knowledge innovation performance of research collaboration teams (Pengcheng Zhang 2011). In addition to the above-mentioned studies, domestic and foreign scholars have conducted many discussions on the effective management of research teams and achieved remarkable results.

In summary, academics have conducted multifaceted studies on the definition, role, performance, influencing factors, and organizational management of research teams, but there is less literature on innovation performance evaluation established at the level of research 
teams. In this paper, with the help of DEA-Tobit two-step method, we try to measure the collaborative innovation performance of agricultural research teams and the direction and degree of influence of each environmental factor on the collaborative innovation performance of agricultural research teams, in order to improve the collaborative innovation performance of agricultural research teams in China and provide an effective path for the development and growth of agricultural research teams in China.

\section{Research Methodology and Data Description}

\subsection{Research Methodology}

In this paper, the DEA model of variable returns to scale (VRS) is used to measure the collaborative innovation performance of agricultural research teams, which operates independently of scale efficiency and the calculation results are real and reliable. In order to further investigate the factors influencing the collaborative innovation performance of agricultural research teams and the degree of influence, the regression analysis of efficiency values on various environmental factors is done based on the analysis of relative efficiency using DEA (Coelli, 1998), and the coefficients of independent variables are used to judge the direction and degree of the effect of environmental factors on efficiency values.

\subsection{Data description}

The group investigated the status of input and output, internal and external environmental factors of some domestic agricultural research innovation teams through interviews, talks and small conference exchanges or conducting questionnaire research, and obtained a set of statistical research data. The statistical data involved a total of 151 agricultural researchers. On the basis of following the conditions of research method application and the principle of homogeneity, the input-output index system of agricultural research team members was determined and assigned values assuming that all members faced the same innovation environment (see Table 1). It can be seen that: there are large differences in input-output data among members of agricultural science and technology teams. 
Table 1 Input and output indicators of collaborative innovation performance of agricultural research teams and statistics

\begin{tabular}{|c|c|c|c|c|c|c|}
\hline Indicator & Carve metrics & dimension & Mean & Std & Max & Min \\
\hline \multirow{3}{*}{$\begin{array}{c}\text { Input } \\
\text { Indicators }\end{array}$} & Expenses & $\begin{array}{c}\text { million } \\
\text { yuan }\end{array}$ & 51.4198 & 21.9728 & 21 & 68.25 \\
\hline & Working hours & Day & 253.7225 & 54.5466 & 72 & 288 \\
\hline & $\begin{array}{c}\text { Cooperation and } \\
\text { exchange }\end{array}$ & times & 19.2297 & 22.9796 & 0 & 145 \\
\hline \multirow{6}{*}{ Output } & $\begin{array}{l}\text { Published } \\
\text { monographs }\end{array}$ & Number & 0.4663 & 0.7659 & 0 & 7 \\
\hline & Published Papers & Part & 2.6942 & 3.6947 & 0 & 20 \\
\hline & Patent filing & item & 0.1346 & 0.5130 & 0 & 3 \\
\hline & $\begin{array}{l}\text { Training of } \\
\text { technical staff }\end{array}$ & $\begin{array}{c}\text { Number of } \\
\text { people }\end{array}$ & 783.333 & 2327.5510 & 0 & 15000 \\
\hline & Promoted varieties & individual & 1.7321 & 2.9789 & 0 & 12 \\
\hline & $\begin{array}{l}\text { Discovering } \\
\text { resources }\end{array}$ & Servings & 8.7081 & 75.2415 & 0 & 224 \\
\hline
\end{tabular}

Note: Working hours, daily working hours are counted as 8 hours and 360 working days a year. When analyzing the data, the data in the table is strictly rounded to four decimal places.

Environmental variables affect the collaborative innovation ability of agricultural research team members to a certain extent. Taking into account the structural characteristics of agricultural research teams and the information obtained, seven environmental variables were selected: title, degree of awareness of team goals, degree of familiarity of team members, team communication, compliance with team expenses, whether the local government supports them, and nature of the supporting unit (see Table 2). 
Table 2 Setting and statistics of environmental variables for collaborative innovation performance of agricultural research teams

\begin{tabular}{|c|c|c|c|c|c|}
\hline Statistical variables & Assignment Description & Mean & Std & Min & Max \\
\hline Title & $\begin{array}{l}1=\text { Professor (researcher), } \\
2=\text { Associate Professor (associate } \\
\text { researcher), } 3=\text { Lecturer (assistant } \\
\text { researcher), } 4=\text { Other }\end{array}$ & 1.3600 & 1.0828 & 1 & 4 \\
\hline $\begin{array}{l}\text { Level of team goal } \\
\text { perception }\end{array}$ & $\begin{array}{c}1=\text { very clear, } 2=\text { clearer, } \\
3=\text { clear, } 4=\text { unclear }\end{array}$ & 1.3800 & 0.6622 & 1 & 4 \\
\hline $\begin{array}{l}\text { Familiarity of members } \\
\text { within the team }\end{array}$ & $\begin{array}{c}\text { 1=very well known, } 2=\text { better } \\
\text { known } \\
3=\text { Knowledgeable, } 4=\text { No } \\
\text { knowledge }\end{array}$ & 1.3533 & 0.6035 & 1 & 4 \\
\hline $\begin{array}{l}\text { Cross-team } \\
\text { communication }\end{array}$ & $1=$ yes, $2=$ no & 1.5733 & 0.4962 & 1 & 2 \\
\hline $\begin{array}{c}\text { Compliance of team } \\
\text { expenses }\end{array}$ & $\begin{array}{c}1=\text { very reasonable, } 2=\text { reasonable, } \\
3=\text { unreasonable }\end{array}$ & 1.5867 & 0.6470 & 1 & 3 \\
\hline $\begin{array}{l}\text { Local government } \\
\text { support }\end{array}$ & $\begin{array}{c}1=\mathrm{No}, 2=\text { Yes, but not very big } \\
3=\text { yes, very big }\end{array}$ & 1.7267 & 0.6745 & 1 & 3 \\
\hline $\begin{array}{c}\text { Nature of the relying } \\
\text { unit }\end{array}$ & $\begin{array}{c}1=\text { Research unit or university. } \\
2=\text { Other (e.g. business) }\end{array}$ & 1.1333 & 0.3411 & 1 & 2 \\
\hline
\end{tabular}

The statistics in Table 2 show that: the current innovation subjects of agricultural research teams in China have a high level of knowledge, and team members have a high degree of awareness of team goals and familiarity among team members; cross-team communication needs to be further strengthened; the use of team funds is relatively standardized, while the survey found that local governments provide some support for the development of agricultural 
research teams, but the role is very limited; universities or research institutes have become important support units for research teams.

\section{The process of empirical analysis}

\subsection{Measurements of collaborative innovation performance of agricultural research teams based on DEA model}

In the first stage, DEAP2.1 software was selected to measure the collaborative innovation performance of agricultural research teams with the input-oriented VRS model. The empirical results show that the mean value of comprehensive efficiency of collaborative innovation in agricultural research teams is 0.3850 , the mean value of pure technical efficiency is 0.8733 , and the mean scale efficiency is 0.4160 under the composite factors of management inefficiency, environment and random interference. This result indicates that under the existing innovation environment and input level, team collaborative innovation efficiency has a $61.5 \%$ upside and more room for improvement (see table 3 ).

Table 3 Mean values of collaborative innovation performance of agricultural research teams measured in the first stage

\begin{tabular}{cccc}
\hline Efficiency Type & CRSTE & VRSTE & SCALE \\
\hline Mean & 0.3850 & 0.8733 & 0.4160 \\
\hline
\end{tabular}

The distribution of the comprehensive efficiency of collaborative innovation of agricultural research teams in the first stage, in which 136 team members have the mean value of the comprehensive efficiency of collaborative innovation below 0.6 , and the proportion is as high as $90.67 \%$, and only 14 team members have the efficiency value above 0.6 , and the proportion is less than $10 \%$ (see table 4 ).

Table4 Distribution of integrated technical efficiency of collaborative innovation of agricultural research teams measured in the first stage

$\begin{array}{llllllll}\text { CRSTE } & <0.1 & 0.1-0.2 & 0.2-0.4 & 0.4-0.6 & 0.6-0.8 & 0.8-0.9 & 0.9-1\end{array}$




\begin{tabular}{|c|c|c|c|c|c|c|c|}
\hline $\begin{array}{c}\text { Number of } \\
\text { samples }\end{array}$ & 46 & 29 & 43 & 19 & 3 & 2 & 9 \\
\hline Proportion (\%) & 30.6667 & 19.3333 & 28.6667 & 12.0000 & 2.0000 & 1.3333 & 6.0000 \\
\hline \multicolumn{8}{|c|}{$\begin{array}{l}\text { The distribution of pure technical efficiency of collaborative innovation in agricultural } \\
\text { research teams shows that the distribution of pure technical efficiency values in the interval of } \\
<0.7 \text { and } 0.7-0.8 \text { is more concentrated, with the proportion of } 39.33 \% \text { and } 40 \% \text { respectively; } \\
\text { the number of team members with efficiency values above } 0.8 \text { is less, with the proportion of } \\
20.67 \% \text { only. Overall, the pure technical efficiency of collaborative innovation in agricultural } \\
\text { research teams performed well. } \\
\text { Table } 5 \text { Distribution of pure technical efficiency of collaborative innovation in agricultural research } \\
\text { teams measured in the first stage }\end{array}$} \\
\hline VRSTE & \multicolumn{2}{|c|}{$<0.7$} & \multicolumn{2}{|l|}{$0.7-0.8$} & $0.8-0.9$ & \multicolumn{2}{|c|}{$0.9-1$} \\
\hline $\begin{array}{l}\text { Number of } \\
\text { samples }\end{array}$ & \multicolumn{2}{|c|}{59} & \multicolumn{2}{|l|}{61} & 13 & \multicolumn{2}{|c|}{18} \\
\hline Proportion (\%) & \multicolumn{2}{|c|}{39.3333} & \multicolumn{2}{|l|}{40.0000} & 8.6666 & \multicolumn{2}{|c|}{12.0000} \\
\hline
\end{tabular}

In terms of the scale efficiency distribution of collaborative innovation in agricultural research teams, the situation is not optimistic, with 129 team members having a scale efficiency value below 0.6 , with a proportion as high as $86 \%$; only 14 team members have a scale efficiency value above 0.8 , with a proportion of only $8.33 \%$.

Table 6 Distribution of the scale efficiency of collaborative innovation of agricultural research teams measured in the first stage

\begin{tabular}{cccccccc}
\hline SCALE & $<0.1$ & $0.1-0.2$ & $0.2-0.4$ & $0.4-0.6$ & $0.6-0.8$ & $0.8-0.9$ & $0.9-1$ \\
\hline $\begin{array}{c}\text { Number of } \\
\text { samples }\end{array}$ & 34 & 29 & 37 & 29 & 10 & 3 & 11 \\
Proportion (\%) & 22.7778 & 19.1667 & 24.4444 & 19.1667 & 6.3889 & 1.1111 & 7.2222 \\
\hline
\end{tabular}




\subsection{Tobit regression analysis process}

To further examine the direction and extent of the role of research environment factors, team vision and on collaborative innovation performance, the following Tobit regression was conducted with the help of EVIEWS5.0 software package, using the three types of efficiency values measured by DEA in the first stage as the dependent variables, and the other team members' titles, the degree of team goal recognition, the degree of familiarity of members within the team, cross-team communication, the compliance of team expenses, the support of local government and The Tobit regression was done with the nature of the relying unit as the independent variables (see Table 7).

Table7 Tobit regression results

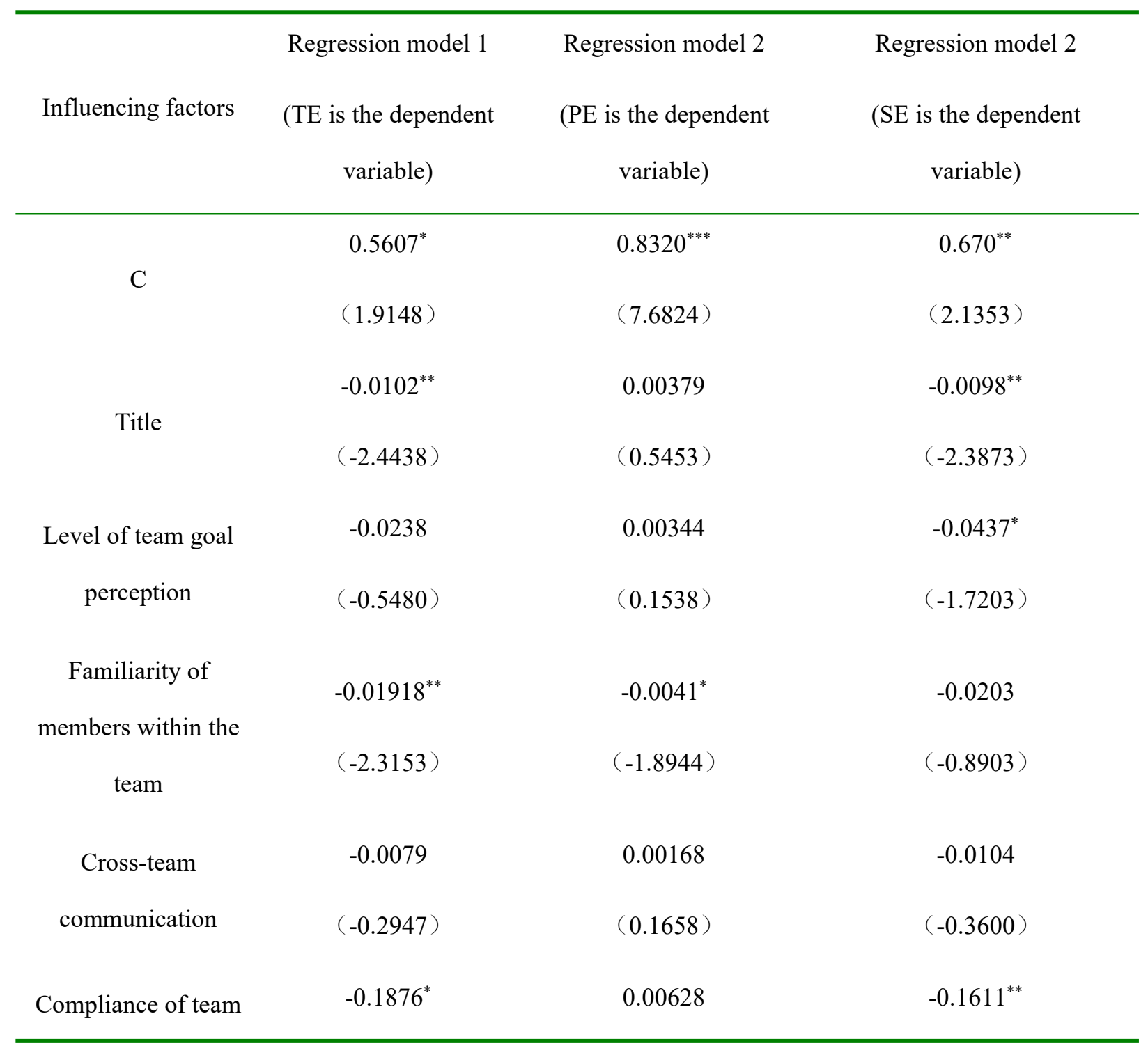




\begin{tabular}{cccc}
\hline expenses & $(-1.6743)$ & $(0.5957)$ & $(-2.0460)$ \\
Local government & -0.0059 & -0.0091 & -0.0029 \\
support & $(-0.2726)$ & $(-1.0541)$ & $(-0.2132)$ \\
Nature of the relying & -0.1516 & -0.0913 & -0.1615 \\
unit & $(-0.4551)$ & $(-0.7852)$ & $(-0.5402)$ \\
Likelihood value & -56.8795 & 320.6433 & -82.4523 \\
\hline
\end{tabular}

Note: Z-statistic values are given in parentheses, and the significance levels corresponding to *, **, and *** are $1 \%, 5 \%$, and $10 \%$, respectively.

Regression model 1 shows that, on the one hand, variables such as the degree of team goal awareness, familiarity of team members within the team, and compliance of funding expenditures have significant negative effects on the collaborative innovation performance of agricultural research teams, indicating that the improvement of agricultural research team members in the degree of team goal awareness, communication and exchange within the team, and compliance of team research funding expenditures will help improve the collaborative innovation performance of the team; on the other hand The effects of environmental variables such as title structure, cross-team communication, local government support, and nature of the supporting units of agricultural research teams on the innovation performance of research teams are not significant, indicating that their effects on team collaborative innovation performance are not statistically significant and can be ignored. The results of regression model 2 indicate that the pure technical efficiency of collaborative innovation in agricultural research teams is only significantly influenced by the variable of familiarity with team members within the team, suggesting that strengthening communication and exchange within agricultural research teams can help improve team management efficiency. The results of regression model 3 show that, on the one hand, the variables of team goal awareness, title structure, and compliance of financial expenditures have significant effects on the scale efficiency of team collaborative innovation, indicating that improving team members' team goal awareness, title structure, and compliance of financial expenditures are conducive to the improvement of the scale efficiency of research team innovation; on the other hand, the 
variables of intra-team member familiarity, cross-team communication On the other hand, the effects of environmental variables such as familiarity of team members, cross-team communication, local government support, and nature of supporting units on the scale efficiency of team collaborative innovation can be ignored.

On the other hand, the environmental variables such as familiarity of team members, cross-team communication, local government support, and nature of the supporting unit have no effect on the scale efficiency of team collaborative innovation. Therefore, optimizing the team title structure, strengthening communication and exchange among team members, and improving and strengthening the fund management system are important directions for the construction of agricultural research teams at present. In addition, probably because the selected agricultural research teams have been established for a short period of time and are still in the exploration stage, the effects of variables such as cross-team communication, local government support, and the nature of the supporting units on the collaborative innovation performance of agricultural research teams are not obvious yet for the sake of getting strong data support.

\section{Conclusions and suggestions for countermeasures}

With the help of research data from core members of agricultural research teams, the innovation efficiency of agricultural research teams was measured using the DEA-Tobit two-step method, and the main factors affecting performance and their directions and degrees of action were analyzed, and the following perceptions were obtained: the team innovation efficiency is low, and the scale inefficiency is the key factor leading to the low team innovation efficiency. Specifically, under the comprehensive consideration of compound factors such as management inefficiency, environment and random interference, the mean value of comprehensive efficiency of collaborative innovation in agricultural research teams is 0.3850 , the mean value of pure technical efficiency is 0.8733 , and the mean scale efficiency is 0.4160 ; the improvement of agricultural research team members' awareness of team goals has a significant effect on the improvement of technical efficiency of team innovation, while 
team members title structure, familiarity of members within the team, and compliance of research expenditure are also important influencing factors for the innovation performance of research teams. In addition, the effects of cross-team communication, local government support, and the nature of the relying unit on the innovation performance of research teams are not supported by strong data and are not yet significant. Synthesizing the above findings, the following countermeasures are proposed.

First, we should increase the financial policy support for agricultural research teams, stabilize the investment mechanism, strengthen the intensity and scale of investment, optimize the allocation structure of financial funds among agricultural research teams and among regions, and steadily improve the scale efficiency of the innovation main body of agricultural research teams. The agricultural research team is both a science and technology research and development center and a huge agricultural science and technology service system with many levels, heavy tasks and wide influence, and the smooth operation of the guarantee period requires the coordination of multiple parties and stable financial support. Firstly, a sound and stable input mechanism should be established to guarantee the sustainable and healthy operation of the agricultural research team; secondly, the allocation of funds should be optimized to achieve the effective integration of agricultural science and technology resources; thirdly, the system of regular exchange of information on the allocation of innovation resources should be improved.

Secondly, we should build an agricultural research team communication and exchange platform, strengthen internal communication and exchange within the team, optimize the title structure of team members and the diversification mechanism of the relying units to maximize scientific and technological output; the construction of the agricultural research team communication platform should start from the common goal of the agricultural research team, take the complexity of the personnel as the consensus, achieve complementary skills and responsibility as the means, and take value realization as the ultimate goal(see Figure 1). 


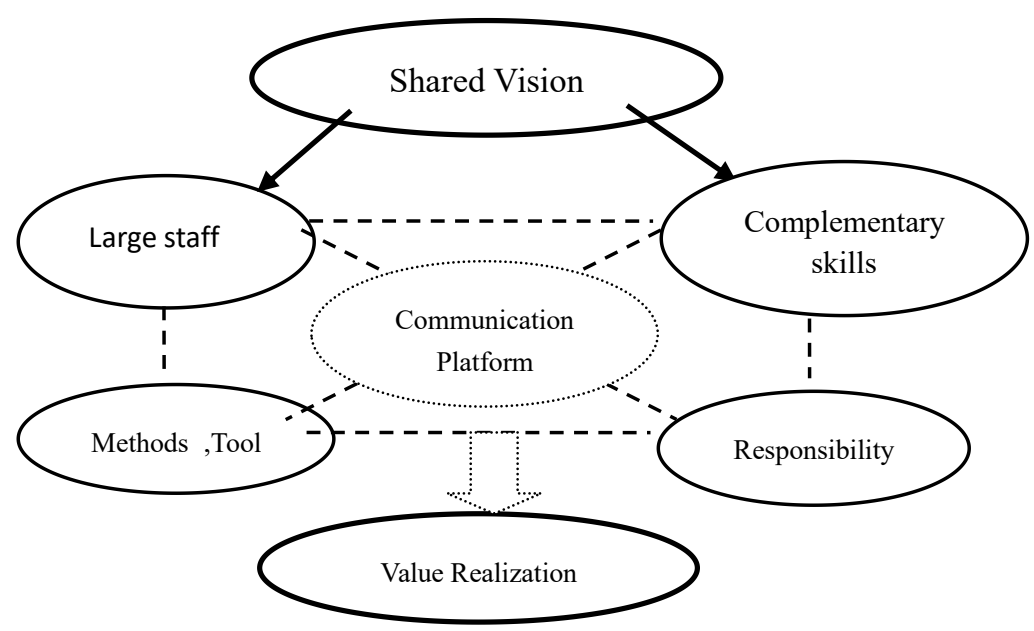

Figure 1 Internal communication mechanism of agricultural research team members

Third, cross-team communication should be strengthened, and teams and departments should cooperate and innovate with each other to create a good collaborative innovation environment for the development of modern agriculture and research teams in China. The sustainable and healthy operation of agricultural research teams requires coordination and collaborative innovation from multiple parties. On the one hand, the support of local government departments for agricultural research teams should be strengthened; on the other hand, a stable cross-team exchange mechanism should be established to achieve nationwide sharing of research resources and create a good collaborative innovation environment for the development of modern agriculture and research teams in China.

\section{References}

[1] Jiang Rifu, Huo Guoqing, Tan Hongjun, Guo Chuanjie. Research on the factors influencing the knowledge innovation performance of scientific research teams--an analysis based on the survey of national scientific research institutions in China[J]. Scientific Research, 2007, 25(2): 365-372.

[2] Wu Yang, Su Jun. Research on the complex characteristics of scientific research team knowledge innovation system and the mechanism of its synergistic mechanism[J]. Science and Technology Research, 2012(01):156-165. 
[3] Eva Kirner,Steffen Kinkel,Angela. "Jaeger innovation paths and the innovation performance of low-technology firms -An empirical analysis of the German industryll,Research Policy,2009,38 (3):447-458.

[4] Shang Runzhi, Long Jing. Innovation management of R\&D teams in high-tech firms: the effects of network structure, transformational leadership on innovation performance [J]. Science Management Research, 2010, 28(5): 76-79.

[5] Jin Linlin. Research on the elements of knowledge management system in university research teams: an empirical analysis from the innovation team of the Ministry of Education[J]. Management Review, 2010, 22(5): 29-34, 55.

[6] Ute R. Hülsheger, Neil Anderson, Jesus F. Salgado. "Team-Level Predictors of Innovation at Work:A Comprehensive Meta- Analysis Spanning Three Decades of Research", Journal of Applied Psychology, 2009,94(5):1128-1145.

[7] Chen Xeguang, Yu Hong, Fan Lijun. Overseas embedding characteristics, knowledge search and innovation performance of R\&D team--an empirical study based on Zhejiang high-tech enterprises[J]. Scientific Research, 2010, 28(1): 151-160.

[8] James D.Adams,Grant C.Black,J.Roger Clemmons.Paula E.Stephan. "Scientific teams and institutional collaborations: Evidence from U.S. universities, 1981-1999", Research Policy, 2005,34(3):259-285.

[9] Hans J. Thamhain, "Managing innovative R\&D teams", R\&D Management, 2003, 33(3): 297-311.

[10] Yuwen Liu, Robert T. Keller and Hsi-An Shih. "The impact of team-member exchange, differentiation, team commitment, and knowledge sharing on R\&D project team performance",R\&D Management,2011,41(3):274-287.

[11] Li Zhihong, Zhu Tao, Lai Wendi. Research on the tacit knowledge sharing willingness of innovative research teams in colleges and universities[J]. Scientific Research, 2010, 28(4):581-590.

[12] Jin Linlin, Li Dehuang. The influence of scientific research team's disciplinary 
background characteristics on innovation performance-using knowledge exchange and sharing and knowledge integration as mediating variables. Scientific Research, 2012(01):111-123.

[13] Geng Zizhen, Liu Xinmei, Shen Li. A study on the mechanism of cooperative goals to promote creativity in research teams[J]. Scientific Research Management, 2012(08):113-119.

[14] Zhang Pengcheng, Peng Han. Research on the relationship between research cooperation network characteristics and team knowledge creation[J]. Research Management, 2011, 32(7): 104-112.

[15] Krsto Pandza, Terry A. Wilkins, Eva A. Alfoldi. "Collaborative diversity in a nanotechnology innovation system:Evidence from the EU Framework Programme",Technovation,2011,31(9):476-489.

[16] Deng Xiuquan, Kang Yunpeng, Xi Junfeng, Bai Bing, Mao Yangshuo. Research on the construction of resource capacity model of university research team and its application[J]. Scientific Research, 2012(01): 102-110.

[17] Xiao Dingding, Zhu Guilong. Research on the construction of core competencies of research teams in universities - using team mental model as a mediating variable [J]. Science and Technology Management, 2012(01):173-180. macos/deepLFree.translatedWithDeepL.text 